\title{
EFISIENSI PEMASARAN KOMODITAS MANGGIS DI KABUPETAN TASIKMALAYA
}

\section{EFICIENCY MARKETING MANGGOSTEEN COMODITY AT TASIKMALAYA DISTRICT}

\author{
Ulpah Jakiyah*, Syahrul Ganda Sukmaya \\ Program Studi Agribisnis Universitas Perjuangan, J1 PETA No 177 Tasikmalaya \\ *Email: ulpahjaki89@gmail.com
}

(Diterima 18-11-2019; Disetujui 20-12-2019)

\begin{abstract}
ABSTRAK
Pemasaran manggis di Kabupaten Tasikmalaya telah mencapai ke berbagai negara salah satunya China. Ekspor manggis dilakukan oleh beberapa distributor manggis yang berada di Kabupaten Tasikmalaya salah satunya PT Java fresh. Harga jual manggis untuk ekspor mencapai Rp 30.000/kg sedangkan harga ditingkat petani berkisar Rp 3500-Rp 5000/kg. Sehingga tujuan penelitian ini adalah untuk mengukur tingkat efisiensi pemasaran manggis untuk kegiatan ekspor di Kabupaten Tasikmalaya. Berdasarkan hasil penelitian yang diperoleh bahwa saluran pemasaran ekspor terdapat dua saluran yaitu manggis dengan kualitas Super (SP). Saluran 1 manggis kualitas SP dari petani disalurkan ke pedagang pengumpul desa (Tengkulak) dengan presentase 70 persen dari jumlah panen. Saluran 2 petani menjual ke pedagang pengumpul kecamatan langsung dijual ke eksportir. Kegiatan nilai tambah pada setiap saluran hanya terdapat pada kegiatan pembersihan dan sortir buah. Marjin pemasaran paling tinggi adalah eksportir dengan distribusi marjin sebesar 56,6 persen pada saluran 1 dan 60 persen pada saluran 2. Sedangkan rasio keuntungan terhadap biaya yang paling besar adalah pengumpul desa. Hal ini dikarenakan biaya yang dikeluarkan relatif lebih kecil dibandingkan lembaga pemasaran lainnya. Berdasarkan efisiensi harga dan operasional, pemasaran manggis efisien dilakukan dikarenakan keuntungan atau selisih harga lebih besar dari biaya yang dikeluarkan oleh setiap lembaga pemasaran.
\end{abstract}

Kata kunci: efisiensi, farmer share, marjin, pemasaran

\begin{abstract}
Marketing mangosteen in Kabupaten Tasikmalaya has reached around the country one of them China. Exports mangosteen carried out by several distributors mangosteen who was in the district of tasikmalaya one of them PT Java Fresh. The selling price mangosteen for export reached rp $30.000 / \mathrm{kg}$ while the price level farmers around $\mathrm{rp} 3500-\mathrm{rp} 5000 / \mathrm{kg}$. So that the purpose of this research is to measure the efficiency mangosteen marketing for export activity in the district. Tasikmalaya based on the research results obtained that export marketing outlets there are two channels that come with the quality of super ( $s p$ ). A channel 1 mangosteen sp quality from the farmers be channeled to merchants (village middleman) with the percentage 70 percent of the harvest.A channel 2 farmers sell to trader sells directly to the exporters. sub districtThe added value to every channel there are only on an activity of cleaning and sorting. Margins marketing the highest is exporters with distribution margin of 56.6 percent of the channel 1 and 60 percent of the channel 2. While the ratio of gains against the most are the intermediary village. This is the cost is relatively small in comparison to other institusions marketing. Based on price and, operational efficiency marketing mangosteen efficient done because advantage or the differences in price greater than the cost by each institution marketing.
\end{abstract}

Keywords: efficiency, farmer share, margins, marketing 


\section{PENDAHULUAN}

Upaya pemerintah dalam meningkatkan ekspor komoditas pertanian berdampak pada kegiatan pemasaran manggis di Kabupaten Tasikmalaya. Keberhasilan petani manggis untuk mengekspor ke berbagai negara antara lain Jerman, China, dan Amerika Serikat. Salah satu pengekspor terbesar komoditas manggis di Kabupaten Tasikmalaya adalah PT Java Fresh. Sejak tahun 2017 sampai sekarang PT Java Fresh telah berhasil mengekspor 2000 ton manggis ke China dan berbagai negara lainnya. Komoditas tersebut merupakan komoditas ekspor andalan Kabupaten Tasikmalaya. Belum adanya data jumlah ekspor buah manggis yang dibukukan dari tahun ke tahun sehingga terdapat kesulitan mengetahui jumlah dan perkembangan ekspor komoditas tersebut dari dinas setempat.

Pemasaran manggis sampai ekspor tidak lain pasti ada keterlibatan petani manggis dalam menghasilkan manggis. Petani melakukan panen atau kegiatan tanam kemudian menjual ke berbagai lembaga pemasaran. Harga jual petani manggis Rp 3500-Rp 5000/kg. sedangkan harga jual ekspor mencapai Rp 30.000/kg. Petani manggis menghadapi ketidak stabilan harga dipasaran. Bahkan ketika musim panen harga yang diterima petani bisa sangat rendah. Perbedaan harga yang signifikan dari setiap lembaga pemasaran bisa juga diakibatkan oleh kurang efisienya lembaga pemasaran yang terlibat dalam ekspor manggis.

Tujuan penelitian ini adalah menginventarisir saluran pemasaran serta fungsi-fungsi saluran pemasaran, menganalisis tingkat efisiensi pemasaran melalui marjin pemasaran, efisiensi harga, dan operasional pada setiap saluran.

\section{METODE PENELITIAN}

Penelitian ini dilakukan di sentra produksi manggis Kecamatan Puspahiang Kabupaten Tasikmalaya. Pemilihan lokasi dilakukan dengan purposive dengan dasar bahwa lokasi ini dekat dengan eksportir manggis. Kegiatan penelitian dilakukan pada bulan April-Agustus 2019. Penentuan sampel dilakukan secara simple random service pada lima desa di Kecamatan Puspahiang sebanyak 35 petani, 4 pedagang pengumpul desa, 5 pedagang pengumpul kecamatan dan 1 eksportir. Data yang dikumpulkan dengan metode wawancara dengan kuesioner.

Analisis secara kuantitaf digunakan dengan analisis marjin pemasaran, efisiensi harga, dan operasional pada setiap lembaga pemasaran (Erlangga, 
2012). Menganalisis efisiensi pemasaram diukur dengan memperhitungkan besarnya harga ditingkat produsen dan konsumen akhir serta biaya tataniaga dan keuntungan dari semua pelaku yang terlibat dalam pemasaran manggis (Saleh L, 2017). Sedangkan perspektif mikro marjin pemasaran merupakan selisih harga jual dengan harga beli atau margin pemasaran merupakan biaya-biaya dan keuntungan dari perusahaan tersebut akibat adanya aktivitas bisnis (Asmarantaka, 2012). Secara matematis model yang digunakan untuk mengukue margin pemasaran adalah :

$$
\begin{array}{r}
M T=P r-P f=\text { Biaya }+\pi \text { lembaga } \\
=\Sigma M i \ldots \ldots \ldots \ldots \ldots
\end{array}
$$

Dimana:

$\mathrm{MT}=$ Margin total

$\mathrm{Mi}=$ Marjin di tingkat lembaga $\mathrm{ke}-\mathrm{i}$ dimana $i=1,2, \ldots \ldots n$

$\operatorname{Pr}=$ Harga di tingkat Konsumen

$\mathrm{Pf}=$ Harga di tingkat produsen

$\Pi$ lembaga $=$ profit lembaga pemasaran akibat adanya sistem pemasaran Pji = Harga penjualan untuk lembaga pemasaran ke-i

$\mathrm{Pbi}=$ Harga pembelian untuk lembaga pemasaran ke- i

Selain marjin pemasaran untuk menghitung efisiensi pemasaran digunakan penilaian Farmer's share. Besarnya Farmer's share dipengaruhi oleh tingkat pemrosesan, biaya transportasi, kaewetan produk, dan jumlah produk. Semakin tinggi Farmer's share menyebabkan semakin tinggi pula bagian harga yang diterima petani. Rumus yang digunakan untuk menghitung Farmer's share:

$\mathrm{FS}=\frac{P f}{P r} \quad \mathrm{X} 100$ persen

dimana:

FS : Bagian harga yang diterima petani $(\mathrm{Rp} / \mathrm{kg})$

Pf : Harga padi organik ditingkat petani (Rp/kg)

Pr : Harga padi organik ditingkat konsumen $(\mathrm{Rp} / \mathrm{kg})$

Pengukuran efisiensi harga manggunakan asumsi struktur pasar yang terjadi adalah persaingan sempurna yaitu pasar dimana terdapat banyak penjual dan pembeli, dan setiap penjual dan pembeli tidak dapat mempengaruhi keadaan pasar (Sukirno, 2002).

a. Biaya transportasi

$$
H i-H(i-1)=B T
$$

\section{Dimana:}

$\mathrm{H}_{\mathrm{i}} \quad$ : harga pada satu kota

$\mathrm{H}_{(\mathrm{I}-1)} \quad$ : Harga pada kota lain

BT : Biaya transportasi 
Kriteria efisiensi harga menurut fungsi transportasi untuk lembaga pemasaran apabila:

$\mathrm{H}_{\mathrm{i}}-\mathrm{H}_{(\mathrm{i}-1)}>\mathrm{BT}$ maka efisiensi tercapai $\mathrm{H}_{\mathrm{i}}-\mathrm{H}_{(\mathrm{i}-1)}>\mathrm{BT}$ efisiensi tidak tercapai

b. Selisih harga jual antar lembaga

$$
\mathrm{HJ}_{\mathrm{i}}-\mathrm{HJ}_{(\mathrm{i}-1)}=\mathrm{BP}_{\mathrm{i}}
$$

Dimana:

$\mathrm{HJ}_{\mathrm{i}} \quad$ : Harga jual lembaga pemasaran ke-i

HJ (i-1) : Harga jual lembaga pemasaran ke-(i-1)

BPi : Biaya pelaksanaan fungsi-fungsi pemasaran lembaga ke-i yang terdiri dari biaya pengepakan, bongkar muat, sortasi dan grading, dan pengemas.

i $\quad: 1,2,3, \ldots \mathrm{n}$, merupakan lembaga pemasaran yang terlibat.

Kriteria efisiensi harga untuk lembaga pemasaran apabila:

$\mathrm{HJi}-\mathrm{HJ}(\mathrm{i}-1)>\mathrm{BPi}$, maka efisiensi tercapai.

HJi - HJ(i-1) < BPi, maka efisiensi tidak tercapai.

Pengukuran efisiensi operasional dapat dilakukan dengan menggunakan Load Factor Efficiency, yaitu bagaimana menggunakan fasilitas yang ada secara optimal (Novita et al, 2013). Fasilitas yang dipakai ukuran adalah fasilitas transportasi yang dihitung berdasarkan satuan ukuran dalam setiap kali pengangkutan jeruk manis, disesuaikan dengan ukuran kendaraan. Apabila kapasitas angkutnya 100\% (full capacity) atau lebih dari $100 \%$ (over capacity) maka dapat dikatakan efisien. Sedangkan apabila kapasitas angkutnya kurang dari $100 \%$, maka dapat dikatakan tidak efisien. Kriteria pengukuran efisiensi operasional dapat dirumuskan sebagai berikut :

$\mathrm{Cp}>100 \%$, maka efisien

$\mathrm{Cp}<100 \%$, maka tidak efisien

Dimana:

Cp : Kapasitas kendaraan dalam mengangkut jeruk manis.

\section{HASIL DAN PEMBAHASAN}

Saluran pemasaran manggis Grade SP terdapat 2 saluran pemasaran Antara lain saluran A sampai dengan saluran $\mathrm{C}$. Hal ini dapat dilihat pada Gambar 1. Hasil studi menunjukkan bahwa di Kabupaten Tasikmalaya hanya memiliki dua orang pembibit manggis kualitas Super. Namun pembibit ini hanya menjual bibit saja tidak melakukan hasil kegiatan panen dari hasil pembibitan. Bibit manggis yang ditanam merupakan bibit turun temurun sehingga petani tidak melakukan pembibitan. Saluran A petani manggis menjual kualitas SP ke pedagang pengumpul Desa dengan harga $\mathrm{Rp} 5.000$ perkilogram. 
Petani menghasilkan dan menjual manggis kualitas SP dengan kisaran presentase 70-30 persen dari jumlah panen. Indikator manggis kualitas SP ini adalah ukuran dan tidak memiliki jentik putih. Petani melakukan kegiatan pembersihan dengan kisaran biaya $\operatorname{Rp} 250$ per kilogram. Petani tidak melakukan kegiatan pengangkutan namun pedagang pengumpul desa langsung datang ke petani. Pedagang pengumpul desa melakukan kegiatan pengangkutan sekitar Rp 1.000/kg dan sortir manggis sekitar Rp 500/kg. Pedagang pengumpul desa menjual ke pedagang pengumpul kecamatan dengan harga Rp 10.000 per kilogram saat persediaan sedikit. Namun saat persediaan melimpah pedagang pengumpul menjual kualitas SP sama dengan kualitas BS sekitar Rp 3.500-Rp 5.000 per kilogram. Pedagang pengumpul kecamatan menjual ke eksportir yaitu PT Java Fresh dan PT Buah Angkasa dengan kisaran Rp 20.000 perkilogram. Saluran B Manggis kualitas SP dari petani langsung dijual ke Pedagang Kecamatan dengan kisaran harga Rp 5.000 per kilogram. Saluran ini terjadi saat lokasi petani dekat dengan pedagang pengumpul besar (kecamatan).

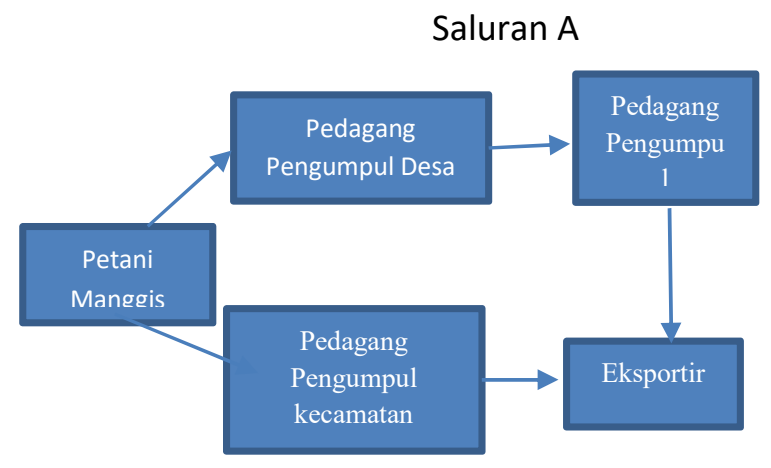

Saluran B

Gambar 1. Saluran Pemasaran Manggis Kualitas Super

Kemudian manggis dipasarkan dari pedagang pengumpul kecamatan ke eksportir dengan Rp 20.000 perkilogram. Setiap harga jual manggis tidak ditentukan oleh petani melainkan pedagang pengumpul desa maupun kecamatan. Penentuan harga juga ditentukan dengan ketersediaan manggis saat tidak musim panen harga jual tinggi namun saat panen raya harga jual kualitas SP sama dengan kualitas BS.

Fungsi pemasaran dilakukan oleh setiap setiap lembaga pemasaran berbedabeda. Namun pada komoditas tidak memiliki perbedaan perlakukan yang siginifikan hanya sebatas sortir dan pembersihan. Hal ini dapat dilihat pada Tabel 1. 
Tabel 1. Fungsi Pemasaran

\begin{tabular}{|c|c|c|c|c|}
\hline Kegiatan & Petani & P.P desa & P.P Kec & Ekspotir \\
\hline Panen & $\sqrt{ }$ & & & \\
\hline Pembersihan & $\sqrt{ }$ & & $\sqrt{ }$ & $\sqrt{ }$ \\
\hline Pengangkutan ke pengumpul desa & $\sqrt{ }$ & $\sqrt{ }$ & & $\sqrt{ }$ \\
\hline Pengemasan & & & & $\sqrt{ }$ \\
\hline Pengangkutan ke pedagang pengumpul kecamatan & & $\sqrt{ }$ & & \\
\hline Pengangkutan ke pasar & & $\sqrt{ }$ & $\sqrt{ }$ & \\
\hline Pengangkutan ke eksportir & & $\sqrt{ }$ & $\sqrt{ }$ & \\
\hline Penjualan & $\sqrt{ }$ & $\sqrt{ }$ & $\sqrt{ }$ & $\sqrt{ }$ \\
\hline Pembelian & & $\sqrt{ }$ & $\sqrt{ }$ & $\sqrt{ }$ \\
\hline
\end{tabular}

Sumber: Data primer diolah, 2019

Pedagang pengumpul desa melakukan pengumpulan manggis dari lahan petani ke pedagang pengumpul kecamatan dan eksportir dengan mengeluarkan biaya angkut, sortir $\mathrm{Rp}$ 1.690/kg (Tabel 2). Pedagang pengumpul desa tidak melakukan penyimpanan dikarenakan permintaan manggis selalu ramai bahkan belum memenuhi permintaan. Pedagang pengumpul kecamatan juga tidak melakukan perlakukan terhadap komoditas manggis hanya sebatas pengangkutan dari pedagang pengumpul desa dan petani ke eksportir. Biaya yang dikeluarkan pedagang pengumpul kecamatan $\mathrm{Rp}$ $2.554 / \mathrm{kg}$ baik ke pasar lokal dan eksportir. Perusahaan eksportir manggis di Kabupaten Tasikmalaya melakukan kegiatan sortasi, pengecekan kualitas, pengemasan dan pengangkutan ke negera
China. Biaya yang dikeluarkan eksportir manggis yaitu Rp 11.135/kg. masingmasing pelaku rantai nilai mengeluarkan biaya dan mengambil keuntungan yang berbeda-beda sehingga harga jual manggis mengalami perbedaan. Dari hasil penelitian yang disajikan pada gambar 1 petani menjual manggis kualitas SP

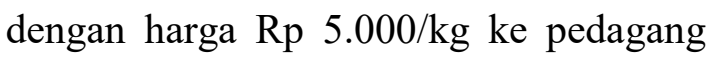
pengumpul. Biaya yang dikeluarkan pedagang pengumpul desa antara lain $\mathrm{Rp}$ 750/kg biaya angkut dan Rp 250/kg untuk pembersihan. Pedagang pengumpul desa mengambil keuntungan sebesar $\mathrm{Rp}$ $1.560 / \mathrm{kg}$ dengan menjual ke pengumpul kecamatan dan keuntungan Rp 750/kg. Struktur biaya dan harga manggis pada setiap lembaga pemasaran dapat dilihat pada Tabel 2. 
Tabel 2. Struktur Biaya Pemasaran Manggsi Kualitas SP

\begin{tabular}{|c|c|c|c|c|}
\hline Kegiatan & $\begin{array}{c}\text { Petani } \\
(\mathrm{Rp} / \mathrm{kg})\end{array}$ & $\begin{array}{l}\text { P. desa } \\
(\mathrm{Rp} / \mathrm{kg})\end{array}$ & $\begin{array}{c}\text { P. Kec } \\
(\mathrm{Rp} / \mathrm{kg})\end{array}$ & $\begin{array}{c}\text { Eksportir } \\
\text { (Rp/kg) }\end{array}$ \\
\hline Produksi & 1.878 & & & \\
\hline Panen & 275 & & & \\
\hline Kemasan & & & & 7.500 \\
\hline Karung & 50 & & 150 & \\
\hline Transportasi dari lahan & & 750 & & \\
\hline Kerugian panen $(2,5 \%)$ & 150 & & & \\
\hline Harga jual & 3.500 & 8.500 & 15.000 & 30.000 \\
\hline Harga beli & & 5.000 & 10.000 & 15.000 \\
\hline $\begin{array}{l}\text { Transportasi lahan ke pedagang pengumpul } \\
\text { kecamatan }\end{array}$ & & & 837 & \\
\hline Transportasi ke pasar & & 457 & 432 & 564 \\
\hline Sortasi & & 200 & 500 & 675 \\
\hline Sortir sisa $(5 \%)$ & & 530 & 635 & 576 \\
\hline Bongkar muat dan sortir & & & & 950 \\
\hline Sisa penyimpanan $(2 \%)$ & & & & 870 \\
\hline Kirim ke pelabuhan & & & & 850 \\
\hline
\end{tabular}

Marjin pemasaran komoditas manggis dilakukan untuk melihat apakah marjin pemasaran telah terdistribusi secara adil dan proporsional pada tiap-tiap lembaga pemasaran yang terlibat dalam suatu kegiatan pemasaran. Berikut rincian rata-rata distribusi marjin dan farmer share pada komoditas manggis kualitas SP pada saluran 1 pada Tabel 3.

Berdasarkan Tabel 3 menunjukkan bahwa harga jual ditingkat petani $\mathrm{Rp}$ $3500 / \mathrm{kg}$ dengan presentase $11.67 \%$ dari harga konsumen. Pedagang pengumpul desa menetapkan harga Rp 8.500/kg dengan presentase $28.33 \%$ dari harga konsumen. Pedagang pengumpul kecamatan menetapkah harga jual $\mathrm{Rp}$ $15.000 / \mathrm{kg}$ dengan presentase $50 \%$ dari harga konsumen. Total marjin pemasaran pada komoditas manggis adalah $\mathrm{Rp}$ $26.500 / \mathrm{kg}$. pedagang pengumpul desa memperoleh marjin $\mathrm{Rp} 5000 / \mathrm{kg}$ yang didistribusikan untuk melaksanakan fungsi-fungsi pemasaran antara lain biaya transportasi Rp 750/kg, biaya sortasi Rp 200/kg, biaya sortir sisa Rp 530/kg dan keuntungan yang diperoleh Rp 3520/kg.

Marjin pemasaran yang diperoleh pedagang pengumpul kecamatan sebesar Rp 6.500/kg yang didistribusikan untuk biaya karung Rp 150/kg, biaya pengangkutan dari pedagang pengumpul

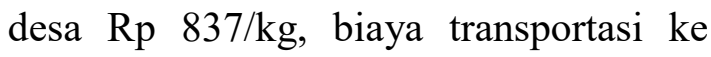
eksportir Rp 432/kg, sortasi Rp 635/kg, sortasi sisa Rp 500/kg, dan keuntungan yang ambil Rp 3946/kg. eksportir memperoleh marjin Rp 15.000/kg yang akan didistribusikan untuk biaya kemasan 


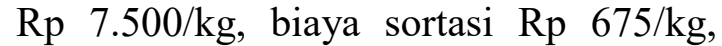
biaya sortasi sisa $\mathrm{Rp} 576 / \mathrm{kg}$, biaya bongkar muat Rp 950/kg, transportasi sisa
Rp 850/kg, sisa penyimpanan Rp 870/kg, dan keuntungan Rp 3579/kg.

Tabel 3. Distribusi Marjin dan Farmers Share pada Saluran 1

\begin{tabular}{|c|c|c|c|c|c|}
\hline Uraian & Nilai (Rp/kg) & Marjin & $\begin{array}{c}\text { Distr marjin } \\
(\%)\end{array}$ & $\begin{array}{c}\text { Distr share } \\
(\%)\end{array}$ & Rasio K/B \\
\hline \multicolumn{6}{|l|}{ Petani } \\
\hline Harga jual & 3.500 & & & 11,67 & \\
\hline Pengumpul Desa & & 5.000 & 18.86 & & 2.37 \\
\hline Harga beli & 3.500 & & & 11.67 & \\
\hline transpor & 750 & & 2.8 & 2.5 & \\
\hline sortasi & 200 & & 0.75 & 0.66 & \\
\hline Sortir sisa & 530 & & 2 & 2.65 & \\
\hline keuntungan & 3.520 & & 13.28 & 11.73 & \\
\hline Harga jual & 8.500 & & & 28.33 & \\
\hline Pedagang Kecamatan & & 6500 & 24.53 & & 1.54 \\
\hline Harga beli & 8.500 & & & 28.33 & \\
\hline Karung & 150 & & 0.56 & 0.5 & \\
\hline Transportasi dr $\mathrm{p}$ desa & 837 & & 3.15 & 2.79 & \\
\hline Transportasi ke Distributor & 432 & & 1.63 & 1.44 & \\
\hline Sortasi sisa & 635 & & 2.39 & 2.11 & \\
\hline Sortasi & 500 & & 1.88 & 1.67 & \\
\hline Keuntungan & 3.946 & & 14.89 & 13.15 & \\
\hline Harga jual & 15.000 & & & 50 & \\
\hline eksportir & & 15000 & 56.6 & & 0.31 \\
\hline Harga beli & 15.000 & & & 50 & \\
\hline Kemasan & 7.500 & & 28.3 & 25 & \\
\hline Sortasi & 675 & & 2.54 & 2.25 & \\
\hline Sortasi sisa & 576 & & 2.17 & 1.92 & \\
\hline Bingkar muat & 950 & & 3.58 & 3.16 & \\
\hline Tranportasi & 850 & & 3.20 & 2.83 & \\
\hline Sisa penyimpanan & 870 & & 3.28 & 2.9 & \\
\hline Keuntungan & 3.579 & & 13.50 & 11.93 & \\
\hline \multirow[t]{2}{*}{ Harga jual } & 30.000 & & & & \\
\hline & & 26500 & 100 & 100 & \\
\hline
\end{tabular}

Sumber: Data primer diolah, 2019

Berdasarkan rasio keuntungan dengan biaya paling besar diperoleh oleh pedagang pengumpul desa yaitu 2.37. Hal ini dikarenakan biaya yang dikeluarkan pedagang pengumpul desa relatif lebih kecil dibandingkan lembaga pemasaran lainnya.

Berdasarkan Tabel 4 menunjukkan bahwa harga jual ditingkat petani $\mathrm{Rp}$ $5000 / \mathrm{kg}$ dengan presentase $16.67 \%$ dari harga konsumen. Pedagang pengumpul kecamatan menetapkan harga $\mathrm{Rp}$ 15000/kg dengan persentase $50 \%$ dari harga konsumen.

Marjin pemasaran yang diperoleh pedagang pengumpul kecamatan sebesar Rp 1.000/kg yang didistribusikan untuk biaya karung $\mathrm{Rp} 150 / \mathrm{kg}$, biaya pengangkutan dari pedagang pengumpul

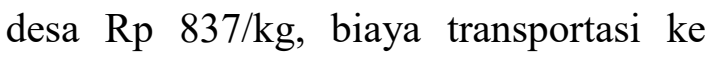


eksportir Rp 432/kg, sortasi Rp 635/kg,

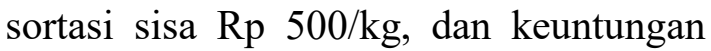
yang ambil Rp 7446/kg. eksportir memperoleh marjin $\mathrm{Rp} 15.000 / \mathrm{kg}$ yang akan didistribusikan untuk biaya kemasan Rp 7.500/kg, biaya sortasi Rp 675/kg, biaya sortasi sisa $\mathrm{Rp} 576 / \mathrm{kg}$, biaya bongkar muat Rp 950/kg, transportasi sisa
Rp 850/kg, sisa penyimpanan Rp 870/kg, dan keuntungan Rp 3.579/kg. dilihat dari rasio keuntungan terhadap biaya pedagang pengumpul kecamatan lebih besar dibandingkan dengan ekportir. Hal ini dikarenakan biaya yang dikeluarkan untuk menjalankan fungsi pemasaran lebih kecil dibandingkan dengan eksportir.

Tabel 4. Distribusi Marjin dan Farmers Share pada Saluran 2

\begin{tabular}{|c|c|c|c|c|c|}
\hline Uraian & $\begin{array}{c}\text { Nilai } \\
\text { (Rp/kg) }\end{array}$ & Marjin & $\begin{array}{c}\text { Distr marjin } \\
(\%)\end{array}$ & $\begin{array}{c}\text { Distr share } \\
(\%)\end{array}$ & Rasio K/B \\
\hline \multicolumn{6}{|l|}{ Petani } \\
\hline Harga jual & 5.000 & & & 16,67 & \\
\hline Pedagang Kecamatan & & 10000 & 40 & & 2.91 \\
\hline Harga beli & 5.000 & & & 16.67 & \\
\hline Karung & 150 & & 0.6 & 0.5 & \\
\hline Transportasi dr $\mathrm{p}$ desa & 837 & & 3.33 & 2.79 & \\
\hline Transportasi ke Distributor & 432 & & 1.73 & 1.44 & \\
\hline Sortasi sisa & 635 & & 2.54 & 2.11 & \\
\hline Sortasi & 500 & & 2 & 1.67 & \\
\hline keuntungan & 7.446 & & 30.21 & 13.15 & \\
\hline Harga jual & 15000 & & & 50 & \\
\hline Eksportir & & 15.000 & 60 & & 0.31 \\
\hline Harga beli & 15.000 & & & 50 & \\
\hline Kemasan & 7.500 & & 30 & 25 & \\
\hline Sortasi & 675 & & 2.7 & 2.25 & \\
\hline Sortasi sisa & 576 & & 2.3 & 1.92 & \\
\hline Bingkar muat & 950 & & 3.8 & 3.16 & \\
\hline tranportasi & 850 & & 3.4 & 2.83 & \\
\hline Sisa penyimpanan & 870 & & 3.48 & 2.9 & \\
\hline Keuntungan & 3.579 & & 14.31 & 11.93 & \\
\hline \multirow[t]{2}{*}{ Harga jual } & 30.000 & & & & \\
\hline & & 25.000 & 100 & 100 & \\
\hline
\end{tabular}

Sumber: Data primer diolah, 2019

Efisiensi pemasaran dilihat dengan efisiensi harga dengan asumsi pasar persaingan sempurna. Pada pasar persaingan sempurna harga mencerminkan biaya yang dikeluarkan. Efisiensi harga ini dihitung dari biaya transportasi dan biaya prosesing. Efisiensi dihitung dari selisih harga komoditi di dua lembaga pemasaran yang harus lebih kecil atau sama dengan biaya yang dikeluarkan untuk melakukan aktifitas tersebut. Tingkat efisiensi harga berdasarkan fungsi biaya transportasi di tiap lembaga pemasaran dapat dilihat pada Tabel 5. 
Tabel 5. Tingkat Efisiensi Harga Berdasarkan Fungsi Biaya Transportasi pada Tiap Lembaga Pemasaran

\begin{tabular}{clcc}
\hline Saluran & Lembaga pemasaran & Selisih harga $(\mathrm{Rp} / \mathrm{Kg})$ & Rata-rata biaya transportasi $(\mathrm{Rp} / \mathrm{kg})$ \\
\hline \multirow{2}{*}{ I } & Pengumpul Desa & 3.520 & 750 \\
& Pengumpul Kecamatan & 3.946 & 1.269 \\
& Eksportir & 3.579 & 1.800 \\
\hline \multirow{2}{*}{ II } & Pengumpul kecamatan & 7.466 & 1.269 \\
& Eksportir & 3.579 & 1.800 \\
\hline
\end{tabular}

Sumber: Data primer diolah, 2019

\section{Berdasarkan fungsi biaya}

transportasi pada tiap lembaga pemasaran bahwa setiap lembaga pemasaran efisien secara harga pada biaya transportasi yang dikeluarkan. Fungsi pemasaran yang diukur tingkat efisiennya berdasarkan pendekatan tingkat harga pada lembaga pemasaran manggis di Kabupaten Tasikmalaya dikatakan sudah efisien, karena rata-rata biaya yang dikeluarkan masih relatif lebih kecil dibandingkan dengan selisih harga.

Pengukuran efisiensi operasional dilihat dari fungsi pemasaran yang dilakukan dan masing-masing fasilitas yang digunakan setiap lembaga pemasaran. Pengukuran ini dilakukan dengan menggunakan standar kapasitas pada masing-masing kegiatan, dalam hal ini adalah transportasi. Sedangkan efisiensi dari fasilitas penyimpanan tidak dilakukan oleh pedagang pengumpul karena manggis yang mudah rusak dan tidak mampu bertahan terlalu lama. Tingkat efisiensi operasional pada fungsi transportasi dapat dilihat pada Tabel 6 .

Tabel 6. Analisis Efisiensi Operasional Menurut Fungsi Transportasi pada Lembaga Pemasaran

\begin{tabular}{clccc}
\hline Saluran & \multicolumn{1}{c}{ Lembaga pemasaran } & Kapasitas normal $(\mathrm{kg})$ & Rata-rata & presentase \\
\hline \multirow{2}{*}{1} & Pengumpul desa & 1.000 & 450 & 45 \\
& Pengumpul kecamatan & 1.000 & 678 & 67.8 \\
& Eksportir & 1.000 & 950 & 95 \\
\hline \multirow{2}{*}{2} & Pengumpul kecamatan & 1.000 & 678 & 67.8 \\
& Eksportir & 1.000 & 950 & 95 \\
\hline
\end{tabular}

Sumber: Data primer, 2019

Pada saluran I dan II, di setiap masing-masing lembaga pemasaran sudah menggunakan fasilitas kendaraan untuk mengangkut komoditi manggis secara efisien dalam melakukan fungsi operasional pengangkutan. Hal ini ditunjukkan dengan penggunaan pick up secara maksimal untuk mengangkut dengan persentase pada tiap saluran pemasaran sebesar $74.12 \%$ Dari penjelasan di atas maka dapat diketahui bahwa masing-masing lembaga 
pemasaran secara operasional sudah efisien dalam menggunakan kendaraan sesuai dengan kapasitas angkutnya.

\section{KESIMPULAN DAN SARAN}

Saluran pemasaran manggis kualitas Super untuk kegiatan ekspor di Kabupaten Tasikmalaya terdapat dua saluran. Setiap saluran memiliki perlakuan yang tidak jauh berbeda yaitu sebatas pembersihan dan sortasi sehingga biaya yang dikeluarkan relative lebih kecil dari keuntungan yang diperoleh. Distribusi marjin paling besar adalah pihak eksportir dengan presentase $56.6 \%$ pada saluran 1 dan $60 \%$ pada saluran 2 . Namun keuntungan terbesar dari kegiatan pemasaran manggis diperoleh pihak pedagang pengumpul kecamatan. Pedagang pengumpul kecamatan berperan aktif dalam kegiatan pemasaran manggis. Pedagang pengumpul kecamatan mengumpulkan buah manggis dari pengumpul desa bahkan petani manggis langsung untuk dijual ke eksportir. Selain itu dari segi efisiensi pemasaran secara harga dan operasional, pemasaran manggis efisien dilakukan. Selisih harga lebih besar dibandingkan biaya-biaya transportasi yang dilakukan dalam pemasaran. Kapasitas pengankutan tidak melebih batas normal. Bahkan eksportir masih memerlukan buah manggis karena permintaan ekspor semakin meningkat.

Saran untuk kegiatan pemasaran adalah perlu adanya distribusi keuntungan dan marjin yang merata dalam setiap lembaga pemasaran. Salah satunya perlu adanya penyuluhan terhadap petani manggis mengenai cara budidaya manggis dikarenakan masih menggunakan bibit jaman dahulu. Kemudian perlu adanya informasi harga yang merata bagi petani sehingga petani tidak menerima harga yang terlalu kecil dibandingkan lembaga pemasaran lainnya. Peran penyuluhan dan pedampingan harus lebih optimal sehingga gapoktan memiliki peran penting dalam kegiatan pemasaran.

\section{UCAPAN TERIMA KASIH}

Kami selaku penulis dan peneliti mengucapkan banyak terima kasih kepada pihak Dikti pada program Penelitian Dosen Pemula (PDP) yang telah membiaya kegiatan penelitian ini sehingga penelitian ini dapat berjalan dengan lancer. Selain itu mengucapkan kepada seluruh rekan-rekan yakni pembantu lapangan, pembantu peneliti dan pihak BPP Puspahiang yang telah membantu kegiatan penelitian ini. 


\section{DAFTAR PUSTAKA}

Asmarantaka RW. 2012. Pemasaran Agribisnis (Agrimarketing). Departemen Agribisnis. Fakultas Ekonomi dan Manajemen. Institut Pertanian Bogor.

Erlangga N, Purwadaria H, Firdaus M. 2012. Improvement of Mangoesteen Farming and Postharvest Handling Strategies on Global gap standard at Kiara Pedes Purwakarta District. Rountable on Sustainable business competitiveness in Indonesian Agribusiness. Jurnal Manajemen dan Agribisnis 9: 69-77.

Hidayat, Hamid. 2002. Metode Penelitian Sosial Ekonomi. Fakultas Pertanian Universitas Brawijaya. Malang.

Irianto, H. 2013. Analisis Value Chain dan Efisiensi Pemasaran Agribisnis Jamur Kuping di Kabupaten Karanganyar. Jurnal SEPA, 9(2): 260-272.
Novita IS, Ratna W, Juniar A. 2013. Analisis Efisiensi Pemasaran Jagung di Provinsi Nusa Tenggara Barat. Jurnal Agribisnis Departemen Agribisnis. Fakultas Ekonomi dan Manajemen. Institut Pertanian Bogor.

Saleh L. 2017. Efisiensi Pemasaran Komoditas Lada di Kabupaten Konawe Ditinjau dari Perspektif Ekonomi Islam. Jurnal Studi Ekonomi dan Bisnis Islam Vol 2 No 1. Lakindede.

Soekartawi, 1987. Prinsip Dasar Ekonomi Pertanian Teori dan Aplikasinya. Jakarta: PT. Rajawali Press.

Sukirno. 2002. Manajemen Agribisnis. Jakarta: Erlangga. 